\title{
Book Review: 21st Century Skills - Learning for Life in Our Times
}

\author{
Murat Ataizi \& Mustafa Donmez \\ Anadolu University, Turkey
}

\begin{abstract}
21st Century Skills (ISBN 978-0-470-47538-6) was published in 2009 by Jossey-Bass, San Francisco, California, United States. The book has a total of 206+xxxi pages. The authors of the book are Bernie Trilling and Charles Fadel. Bernie Trilling is founder and CEO of 21st Century Learning Advisors, and the former global director of the Oracle Education Foundation. He has worked on various pioneering educational products and services and he is an active member of a number of organizations dedicated to bringing 21st century learning methods to students and teachers around the world. Charles Fadel is founder and chairman of the Center for Curriculum Redesign and the Fondation Helvetica Education, and the former Global Education Lead at Cisco Systems. He has engaged with a wide variety of education ministries or boards and has worked on education projects in more than thirty countries.
\end{abstract}

The book aims to provide insight into education in the 21st century. It offers practical advice and comprehensive information on 21st century skills, and collection of skills, knowledge, and attitudes required in this age for educators, policymakers, school administrators, parents, and students. The idea behind the book is that there have been so many drastic transformations in the last few decades and the shifts in how skills like critical thinking and problem solving are learned and practiced in everyday life have been inevitable. The book comes with a video DVD aimed at helping readers illustrate and support the main themes in it. The video DVD contains authentic examples of classrooms and educational programs selected to highlight how teachers and students can tackle real-world problems, learn content knowledge, and build proficiency of 21st century skills.

The book is divided into three parts by first introducing the conditions underlying the 21st century (Part One), then explaining the nature of primary 21st century skills (Part Two), and finally focusing on the practical aspects of 21st century learning (Part Three). The 21st century skills covered in the book can be placed in three categories: (a) Learning and innovation skills: Critical thinking and problem solving, Communications and collaboration, and Creativity and innovation; (b) Digital literacy skills: Information literacy, Media literacy, and Information and communication technologies (ICT) literacy; and (c) Career and life skills: Flexibility and adaptability, Initiative and self-direction, Social and cross-cultural interaction, Productivity and accountability, and Leadership and responsibility.

In Part One, "What Is 21st Century Learning?", Chapter 1, "Learning Past and Future", begins with the transition from Industrial Age to Knowledge Age and its reflection in careers at the beginning of the 21st century, and the new roles education and learning are now playing. This chapter makes a retrospective analysis of the role education has played on social structure, and then explores the professional world that prospective students are expected to face as well as future professions and careers in the 21st century. 
The authors assume that jobs in the 21st century can be categorized as routine jobs (e.g. bookkeepers), manual jobs (e.g. truck drivers), and complex thinking and communicating jobs (e.g. managers, designers), and envisage that creative work will be performed by more developed countries. The authors add that the two essential skill sets that will remain at the top of the list of job requirements for 21st century work are the ability to quickly acquire and apply new knowledge and the know-how to apply essential 21st century skills. The chapter concludes that humanity's historic shift to a 21st century Knowledge Age has profoundly altered what is needed and cherished in modern people's work, learning, and life and that the new world of careers is demanding ever higher levels of expert thinking and complex communicating.

Chapter 2, "The Perfect Learning Storm", examines the four powerful and extraordinary forces that are converging and leading us toward new ways of learning for life in the 21st century: Knowledge work, Thinking tools, Digital lifestyles, and Learning research. These forces are claimed to tilt both what we need to learn and how we will learn to be successful individuals (i.e. students, workers, and citizens) of the 21st century.

The chapter also assesses "The Forces of Resistance" such as Industrial Age education policies, Educational accountability and standardized testing systems, The sheer momentum of decades of direct instruction, The combined weight of the educational publishing industry, The fear among some educational organizations, The traditional preferences of parents.

This chapter finally presents examples of the kinds of new learning most in tune with the 21st century and concludes that offering every child a 21st century education is the real challenge, which will gradually overcome all other collective challenges.

Part Two, "What Are 21st Century Skills?, analyzes the essence of the pivotal 21st century skills. Chapters 3, 4, and 5 deal with the three sets of skills most in demand in the 21st century: Learning and innovation skills; Information, media, and technology skills; and Life and career skills, respectively. Each of these chapters illustrates how these skills are learned in an innovative learning project called ThinkQuest.

Chapter 3 discusses the first area of 21st century skills, learning to learn and innovate, which is claimed to be the key to unlocking a lifetime of learning and creative work: Critical thinking and problem solving (also called expert thinking), Communication and collaboration (complex communicating), and Creativity and innovation (applied imagination and invention).

Chapter 4 describes digital literacy skills that are needed by the future generations to exercise the unparalleled power granted to them by massive amounts of information, media, and technology: Information literacy, Media literacy, and Information and communication technology (ICT) literacy. The authors suggest in this chapter that these digital literacy skills are continually evolving, and they are all essential to managing our ever-expanding tool sets of information, media, and communications technologies.

Chapter 5 describes the life and career skills, which are demanded more and more as technology enhances learning, work, and life in the 21st century: Flexibility and adaptability, Initiative and self-direction, Social and cross- cultural skills, Productivity and accountability, and Leadership and responsibility. 
Part Three, "21st Century Learning In Practice", deals with the practical issues related to the implementation of 21 st century skills.

Chapter 6 discusses the two key tools that, the authors suggest, may be the most powerful learning tools, motivations for learning ever devised: Questions and the process to uncover their answers and Problems and the inventing of their possible solutions. The authors suggest in this chapter that a 21st century learning model utilizing the power of engaging questions and problems can ensure deep interest, understanding, caring, and the application of 21st century skills to real-world challenges.

Chapter 7 introduces a new model for 21st century learning practice driven by questions and problems called "the Project Learning Bicycle", which has four project phases: Define, Plan, Do, and Review. The chapter further points out to the significance of inquiry, design, and collaborative approaches to learning for meeting the rising demand for creativity and innovation.

Chapter $\mathbf{8}$ first presents proofs for the learning value of the Project Learning Bicycle model and then the interlinked support systems that must all work together: Standards, Assessments, Curriculum and instruction, Professional development, and Learning environments. The authors explain how these educational support systems should transform and work together to move learning toward a 21st century design. The chapter then gives examples from one school system, West Virginia, to provide details on one successful approach. Chapter 8 concludes with a prediction that learning will evolve from skills-based to expertise-based as human beings move further into the 21st century.

Chapter 9, the Conclusion, illustrates how future generations may locate lifelong learning in the center of their lives and how online services connecting each individual around the world can help future generations equip themselves with 21st century skills. The chapter finally points out that collaborative 21st century design projects can engage students and citizens around the world to build a better world.

In addition to the chapters, the three Appendixes at the end of the book provides 21st century learning resources, information about the Partnership for 21st Century Skills and its learning model, and a useful formula for remembering the key 21 st century skills (e.g. $3 R s \times 7 C s$ ).

In conclusion, this book provides a brief account of why and how the global conditions of learning have been evolving, and what the 21st century skills movement may bring for each society around the world. The book is well-written and well-organized. It adds significantly to the literature as it provides parents, teachers, school administrators, and policymakers with guidelines about skills, competencies, and flexibilities tailored for our times on the road to learning in the 21st century.

Correspondence: Murat Ataizi, Associate Professor, Faculty of Communication Sciences, Anadolu University, Yunus Emre Campus, Eskisehir, Turkey 